Chapter 22

\title{
Sialyl Salivary-Type Amylase Associated with Ovarian Cancer
}

\author{
Takanori Moriyama \\ Additional information is available at the end of the chapter \\ http://dx.doi.org/10.5772/55452
}

\section{Introduction}

\subsection{Review of related literature}

Studies of tumor-producing amylase originated with Weiss et al.'s 1951 report illustrating a case of bronchogenic carcinoma associated with elevated serum amylase levels [1]. Since then, many reports have focused on lung cancer-producing amylase [2-11], and there have been similar reports in pancreatic [12], stomach [13], uterine [14], and ovarian cancers [15, 16]. Moreover, there have been reports of non-epithelial amylase-producing osteosarcoma [17] and multiple myeloma [18-20]. In these cases, the amylase had the salivary phenotype. However, pancreatic-type amylase has been reported in one case of uterine cancer [21] and two cases of breast cancer [22, 23]. Among those reported cases, determine of the total amylase activity in the sera and amylase isoenzyme electrophoretic analysis have been contributed much to the diagnosis and treatment.

In contrast, Sudo and Kanno [24] reported so-called sialic-acid-containing amylase in the sera of patients with lung and pancreatic cancer. It was similarly detected in the sera of patients with IgA-type [25] and IgD-type multiple myeloma [26], and identified to be sialyl salivarytype amylase by electrophoretic study with neuraminidase treatment and immunological characterization [26]. In 2004, Shigemura et al. [27] demonstrated, using cell culture and immunohistochemical techniques, that sialyl salivary-type amylase, together with normal salivary amylase (defined by electrophoretic characteristics), was produced by myeloma cells. In 2006, Yokouchi et al. [28] also detected the same type of amylase in culture medium from the amylase-producing lung adenocarcinoma cell line IMEC-2. In 2008, the author reported that the characterization of sialyl salivary-type amylase associated with ovarian cancer using conserved sera that were obtained from a retrospective study of amylase zymograms [29]. That 
by this paper, universally seen sialyl salivary-type amylase has been revealed in the patients' sera with those malignancies.

\subsection{Ovarian cancer-producing amylase}

When you focus on ovarian cancer-producing amylase, many studies have been published so far [30-46]. In these reports, the important thing is the following three points.

1. Amylase is directly produced from tumor cell and it can be thought of as of one of the important tumor marker.

2. Serum levels of amylase is decreased after removal the tumor and/or treatments.

3. The phenotype has been deflected to the salivary-type.

In those reports [30-46], in 1988, Henriksen and Brock had been already reported about "fastmigrated amylase isoenzymes" in the patient's serum, cyst fluid, and tumor tissue. They reported that electrophoretic separation of the amylase revealed fast-migration forms in serum 10 of $47(21.3 \%)$ patients with malignant ovarian neoplasms. Unfortunately, they did not characterize the fast-migrating amylase isoenzyme forms [45], however, it is considered in the perspective of today think and as "sialyl salivary-type amylase" similar to our reports [25, 28, 29]. In the following, describe the research results that led to the identification of the amylase found in the sera with ovarian cancer.

\section{Materials and methods}

\subsection{Subjects}

Three patients' sera were chosen from strictly retrospective observation of routine amylase isoenzyme electrophoresis data, 2,850 specimens, which were analyzed from April 1988 to March 1999 in the Clinical Laboratory, Asahikawa Medical College Hospital, Hokkaido, Japan. The criteria were: a S3 to S2 ratio of over 1.0 and/or acidic fast-migrated sub-bands from S4 to S6. The sera were stored at $-80^{\circ} \mathrm{C}$ until required.

A sample with a normal amylase isoenzyme electrophoretic pattern was used as control in the analyses of neuraminidase treatment, reaction with anti-salivary monoclonal antibody, and size-exclusion HPLC.

\subsection{Measurement of total amylase activity}

Total serum amylase activity was measured on a Hitachi 7170 automated analyzer with G4$\mathrm{CNP}$ as substrate (Toyobo, Osaka, Japan) at $37^{\circ} \mathrm{C}$. The reference interval of total serum amylase activity was from 40 to $160 \mathrm{U} / \mathrm{L}$. 


\subsection{Amylase isoenzyme electrophoresis}

The electrophoresis was performed for $60 \mathrm{~min}$ at $300 \mathrm{~V}$ using a cellulose acetate membrane (Titan III lipo, Helena Labs, Beaumont, TX, USA) with discontinuous buffer system [47]. Amylase activity was detected by blue starch staining, according to the technique described by Leclerc and Forest [48]. This electrophoretic technique is the most convenient way to have a high resolution.

\subsection{Treatment with neuraminidase}

Neuraminidase from Arthrobacter ureafaciens (specificities: $\alpha-2 \rightarrow 3, \alpha-2 \rightarrow 6$ and $\alpha-2 \rightarrow 8$ ) and Clostridium perfringens (specificities: $\alpha-2 \rightarrow 3$ and $\alpha-2 \rightarrow 6$ ) were purchased from Nakalai Tesque (Kyoto, Japan) and Sigma (St. Louis, MO, USA), respectively. Neuraminidase treatment was performed at $37^{\circ} \mathrm{C}$ for $1 \mathrm{~h}$ and the treated sample was analyzed by amylase isoenzyme electrophoresis. It was confirmed, using samples from previous reports that the results of both treatments did not differ between whole serum and a purified amylase fraction sample obtained by size-exclusion chromatography $[25,26]$. Whole sera were used for this treatment and the next reaction with monoclonal antibody, because the sample volumes were very low.

\subsection{Reaction with anti-human salivary monoclonal antibody}

Inhibitory monoclonal antibody against human salivary amylase was obtained from an amylase isoenzyme PNP kit (Roche Diagnostics, Tokyo, Japan) based on the method of Gerber et al. [49]. The monoclonal antibody solution was concentrated 5-fold with Minicon B15 clinical sample concentrators (Millipore, Billerica, MA, USA). The monoclonal antibody binds specifically to salivary amylase and inhibits $c a .90 \%$ of total activity. The whole serum was mixed with this antibody, and incubated at $37^{\circ} \mathrm{C}$ for $1 \mathrm{~h}$ then at $4^{\circ} \mathrm{C}$ for $18 \mathrm{~h}$. After the reaction, amylase isoenzyme electrophoresis of the mixture was performed.

\subsection{High performance liquid chromatography (HPLC)}

Size-exclusion HPLC analysis was carried out on a Pharmacia (Uppsala, Sweden) fast-protein liquid chromatography (FPLC) apparatus with a Superose $12 \mathrm{HR}$ column $(30 \mathrm{~cm} 1.0 \mathrm{~cm})$ [50]. The serum $(100 \mu \mathrm{L})$ was eluted with a phosphate buffer $(50 \mathrm{mmol} / \mathrm{L}, \mathrm{pH} 7.2)$ containing $\mathrm{NaCl}$ $(150 \mathrm{mmol} / \mathrm{L})$. The volume of each fraction was $0.8 \mathrm{~mL}$. Protein was monitored by absorbance at $280 \mathrm{~nm}$, and amylase activity (absorbance at $600 \mathrm{~nm}$ ) was monitored with an amylase test kit purchased from Iatoron Labs, Tokyo, Japan.

\section{Results}

3.1. Ages, serum total amylase activities, amylase isoenzyme electrophoretic analyses, and clinical diagnoses of selected sera

Three specimens came from female patients, and afterward it was found out that they had been diagnosed with ovarian cancer based on medical histories. The patients' ages, total serum 
amylase activities, and amylase isoenzyme electrophoretic data at the time of amylase electrophoretic analysis are summarized in Table 1 . Their total amylase activities were 300, 772 , and $798 \mathrm{U} / \mathrm{L}$ and the ratios of activity to the upper reference interval were $1.88,4.20$, and 4.99 , respectively. Amylase isoenzymes with abnormal anodic migration were detected in all three patients' sera and are shown in Fig. 1A (lane 3), B (lane 3), and C (lane 3). Table 1 gives the ratios of total fast-migrated isoenzymes to $\mathrm{S} 1$ and S2 isoenzymes ((S3+S4+S5+S6)/(S1+S2)) and of S3 to S2 (S3/S2). These ratios approximately indicate the proportion of sialyl salivarytype amylase in the total salivary amylase fraction. In cases 2 and 3, the S3 sub-bands were slightly more dominant than the S2 sub-bands, but the ratio of S3 to S2 was below 1.00 only in case 1 . The ratio of abnormal anodic bands (from S3 to S6) to normal salivary sub-bands (S1 and S2) was highest for case 3. Unfortunately, these cases were not recognized as having an abnormal amylase pattern in the routine electrophoretic analyses. It was considered that the S3 sub-bands were obviously dominant over the S2 sub-band in previous cases of multiple myeloma $[25,26]$; this was less pronounced in the cases here.

\subsection{Neuraminidase treatment}

The serum samples of the three cases were treated with neuraminidase and submitted to electrophoretic analyses. The results using neuraminidase from Arthrobacter ureafaciens are shown in Fig. 1A (lane 2), 1B (lane 2), and 1C (lane 2). The abnormal anodic bands (from S3 to S6) showed a reduction of electrophoretic mobility compared with those in untreated sera, and shifted to the cathodic side corresponding to normal salivary isoenzymes in all cases. Both S1 and S2 bands were resultantly stained more strongly, respectively. These densitometric data are shown in Table 1 together with original amylase isoenzyme data. Neuraminidase from Clostridium perfringens had similar effects (data not shown). Therefore, it was considered that the binding pattern of the sialic acid residue was $\alpha-2 \rightarrow 3$ or $\alpha-2 \rightarrow 6$ in those cases. It has been previously confirmed that normal serum shows no change in electrophoresis under the same neuraminidase treatment conditions [25].

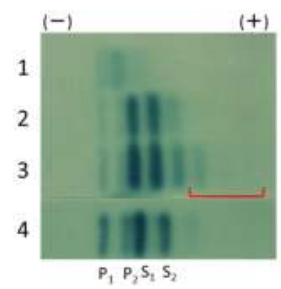

(a)

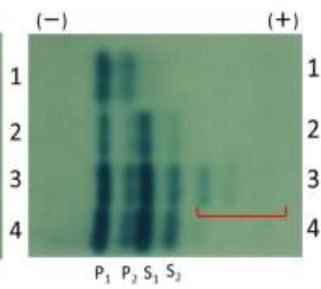

(b)

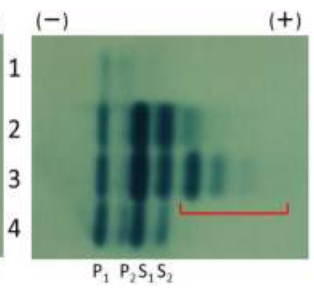

(c)

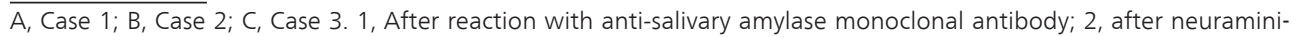
dase treatment; 3 , patient's original serum; 4, normal serum. The fast-migrated amylase isoenzymes were indicated by the bracket.

Figure 1. Amylase isoenzyme electrophoretic analysis of three patients' sera treated with anti-salivary monoclonal antibody and neuraminidase. 


\subsection{Reaction with an anti-salivary amylase monoclonal antibody}

The fast-migrating bands found in the three cases disappeared from the electrophoretic patterns, together with residual normal salivary bands, on reaction with the anti-salivary amylase monoclonal antibody, and a faint broad band of amylase activity was observed on the original patterns. Formation of the faint broad band is evidence that the fast-migrating amylase reacted completely with the monoclonal antibody [25]. These results are shown in Fig. 1A (lane 1) 1B (lane 1), and 1C (lane 1), respectively. It was confirmed previously that the salivary amylase bands in normal serum disappeared from the electrophoretic pattern following similar treatment [25].

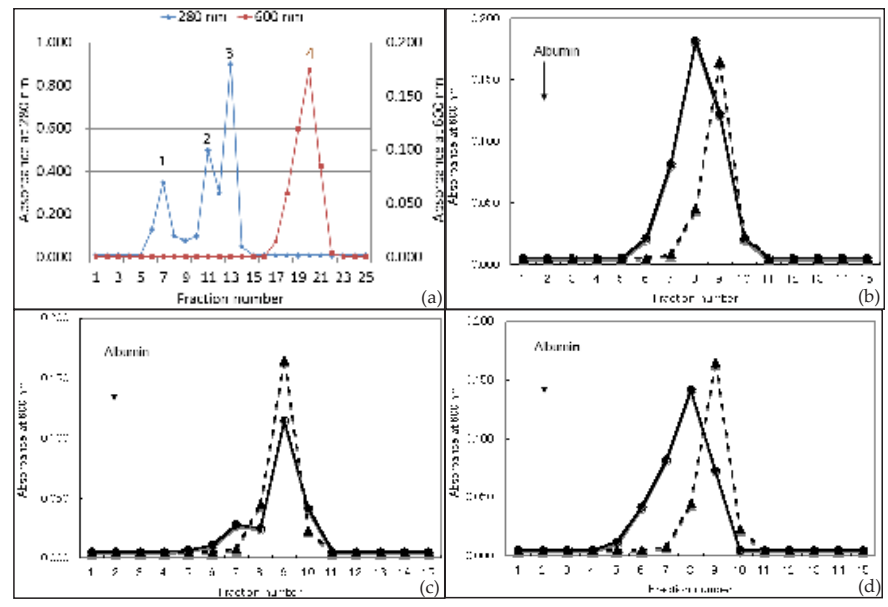

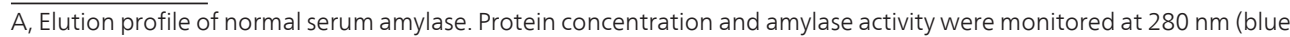
line) and $600 \mathrm{~nm}$ (red line), respectively. Peak 1, IgM; peak 2, Ig ; peak 3, alubumin; peak 4, normal amylase. B, Elution profile of amylase in the serum of case $1 ; C$, that of case 2; D, that of case 3. Amylase activity was monitored at $600 \mathrm{~nm}$. Amylase activities of normal and patient were indicated by the broken line and solid line, respectively. In case 1 and 3, amylase activity was eluted in a broad peak. In case 2, amylase activity was eluted in two peaks. Fraction numbers 7 and 9 correspond to the peak of sialyl salivary-type amylase and the normal serum amylase, respectively.

Figure 2. Elution profiles of amylase from normal serum and three patients' sera by HPLC on a Superose 12 HR column.

\subsection{HPLC analysis}

Normal serum and the patients' sera were subjected to HPLC using a Superose 12 column, and the elution patterns are shown in Fig. 2. Typically, normal serum amylase is eluted as a single peak far from sharp in the low-molecular-weight albumin, indicated in Fig. 2A. From Fig. 2B to 2D, elution patterns of the three cases are shown in comparison with normal amylase peak. Normal serum amylase eluted in fraction number 9, illustrated with a broken line. In contrast, two amylase activity peaks were noted in case 2, in fractions 7 and 9 (Fig. 2C). In cases 1 and 3 , the amylase activity eluted in a large peak, fraction number 8 (Fig. 2B and D). It has been confirmed using isoamylase electrophoretic characterization that fraction 9 corresponds 
to normal salivary and pancreatic amylase, fraction 8 corresponds to a mixture of fastmigrating abnormal amylases with normal amylases, and fraction 7 corresponds to the fastmigrating abnormal amylase [25].

\section{Discussion}

The fast-migrating amylase isoenzyme bands found in the three cases of ovarian cancer were determined to be a sialyl salivary-type amylase from the following results:

1. The isoenzyme bands showed reduced electrophoretic mobility to the cathodic side following neuraminidase treatment.

2. The isoenzyme bands disappeared from the amylase zymograms, and faint broad bands were formed, on reaction with anti-human salivary amylase monoclonal antibody.

3. The isoenzyme bands could be separated by Superose $12 \mathrm{HR}$ size-exclusion HPLC. Thus, an apparent extra high-molecular-mass peak was observed on the chromatogram.

These characteristics of sialyl salivary-type amylase were also demonstrated in the author's first report of myeloma [25]. The three characteristics above were considered simultaneously as strict criteria to detect sialyl salivary-type amylase. The author would like to recommend that, in the future, at least neuraminidase treatment and size-exclusion HPLC analysis should be used for identification.

Many investigators have reported amylase-producing ovarian cancer and reported that serum amylase is an important tumor marker [15, 30-44]. In particular, amylase isoenzyme electrophoresis has been helpful $[6,32]$ in making an early diagnosis and distinguishing from pancreatitis; the amylase phenotype was generally salivary. In contrast, there have been a few unique reports [30, 40, 44, 45] describing acidic amylase and/or fast-migrating amylase found in the sera or ascites associated with ovarian cancer. Unfortunately, neuramidase treatment and characterization of other properties were not performed in these studies. The author considers those amylases, from the findings of this and previous reports [25-28], to be most likely sialyl salivary-type. It seems likely that sialylated salivary-type amylase is directly produced together with normal salivary amylase by ovarian cancer cells, as in multiple mylelona cells [27] and lung cancer cells [28].

In contrast, acidic amylase from ovarian cystic fluids [51,52] can be distinguished clearly from sialyl salivary-type amylase because the cystic amylases are unaffected by treatment with neuraminidase. These amylases are thought to result from aging transformation of cystic amylase, as reported by Warshaw and Lee [53], and Weaver et al.[54]. Therefore, neuraminidase treatment is expected to provide a very important and useful means of distinguishing between aging salivary amylase and sialyl salivary-type amylase. For contrast, we previously published the electrophoretic pattern of aging sialyl salivary-type amylase in pleural effusion with IgD-type multiple myeloma [26].

Size-exclusion HPLC characteristic is another important means of distinguishing sialyl salivary-type amylase from normal salivary amylase. The molecular mass of sialyl salivary- 
type amylase from myeloma was determined by immunoblotting to be approximately 60,000 $\mathrm{Da}$, the same as normal salivary amylase [25]. Unfortunately, the equivalent experiment could not be repeated in this study, owing to the small serum sample sizes, but as the elution profiles in this report were the same as in previous reports [25-28], the molecular mass is assumed to be the same. However, the sialyl salivary-type amylases were well separated by Superose 12 HPLC analyses. Moreover, the peak of the amylases did not change following neuraminidase treatment; such elution behavior can probably be explained by the unusual protein conformation of this abnormal salivary-type amylase [25].

Recently, Shigemura et al.[55] reported that sialyl salivary-type amylase was detected in serum from 7 out of 11 (63.6\%) subjects with multiple myeloma. It was emphasized that sialyl salivarytype amylase is a useful marker of disease activity in multiple myeloma, and that sialylation of the amylase molecule might be concerned with oncogenic transformation or chromosomal abnormalities. Moreover, it was disclosed that sialyl salivary-type amylases could be detected in the serum of patients with a normal serum amylase level and apparently normal electrophoretic patterns. In our cases, although even cases 2 and 3 were not recognized at the time of the samples were taken, the electrophoretic pattern of case 1 was close to normal. However, there certainly were some (small) abnormal fast-migrating sub-bands; those observations were extremely significant. Accordingly, if amylase isoenzyme electrophoresis is more widely and carefully applied to hyperamylasemia with ovarian cancer, it seems likely that more cases will be detected. Serum sialyl salivary-type amylase will no doubt prove a useful marker of ovarian cancer, as for multiple myeloma [55].

In this study, a case of salivary amylase genetic variant [56] might be experienced by unexpectedly. In amylase zymogram of case 1, S2 sub-band was equal or dominant to S1 sub-band. However, further studies could not be performed in this study and there are no evidences. Isoamylase analysis of saliva and/or tumor extract should been carried out to characterize the variant [57].

Sialyl salivary-type amylase has been found in the sera of patients with lung cancer [24, 28], pancreatic cancer [24], multiple myeloma [25], and ovarian cancer [29]. Therefore, it is expected that the sialyl salivary-type amylase will be found generally in patients with amylaseproducing tumors. The author especially recommends that amylase isoenzyme electrophoresis should be applied to hyperamylasemia with malignancies, in place of immunological amylase isoenzyme analysis [49] or that a rapid immunological technique for sialyl salivary-type amylase should be developed in future.

Zakrzewska and Pietrynczak [58] had already elucidated that the total serum and urinary amylase activity and salivary isoenzyme were significantly decreased after surgical removal of the tumor with different types of ovarian cancer. Moreover, they demonstrated that those activities in the serum of the patients with ovarian carcinoma with various types were significantly decreased after radiotherapy [59]. Although the frequency of salivary amylase and/or sialyl salivary-type amylase in ovarian cancer has not been revealed those amylase could be definitely considered as a nonspecific tumor maker [60]. Therefore, the author would like to propose that this old and new amylase should be added with standard tumor marker CA125 [61, 62] in the routine treatment and surgery in ovarian cancer 


\section{Conclusion}

Sialyl salivary-type amylase was detected in the sera of the patients with ovarian cancer. The amylase was considered to have been directly produced together with salivary-type amylase from tumor cells. These studies have contributed to the research into amylase-producing tumors, particularly into amylase-producing ovarian cancer.

\section{Acknowledgements}

The author extremely grateful to the deceased Professor Tatsuo Tozawa, Department of Laboratory Medicine, Hyogo College of Medicine, Nishinomiya, Hyogo, Japan, for encouragement and helpful discussions.

\section{Author details}

Takanori Moriyama

Address all correspondence to: moriyama@hs.hokudai.ac.jp

Medical Laboratory Science, Faculty of Health Sciences, Hokkaido University, Kitaku, Sapporo, Japan

\section{References}

[1] Weiss MJ, Edmondson HA, Wertman M. Elevated serum amylase associated with bronchogenic carcinoma; report of case. Am J Clin Pathol. 1951 Nov;21(11):1057-61.

[2] Ammann RW, Berk JE, Fridhandler L, Ueda M, Wegmann W. Hyperamylasemia with carcinoma of the lung. Ann Intern Med. 1973 Apr;78(4):521-6.

[3] Gomi K, Kameya T, Tsumuraya M, Shimosato Y, Zeze F, Abe K, et al. Ultrastructural, histochemical, and biochemical studies of two cases with amylase, ACTH, and betaMSH producing tumor. Cancer. 1976 Oct;38(4):1645-54.

[4] Yokoyama M, Natsuizaka T, Ishii Y, Ohshima S, Kasagi A, Tateno S. Amylase-producing lung cancer: ultrastructural and biochemical studies. Cancer. 1977 Aug;40(2): 766-72.

[5] Morohoshi T, Nakamura N, Hayashi K, Kanda M. Amylase producing lung cancer. Electronmicroscopical and biochemical studies. Virchows Arch A Pathol Anat Histol. 1980;387(2):125-32. 
[6] Maeda M, Otsuki M, Yuu H, Saeki S, Yamasaki T, Baba S. Salivary-type hyperamylasemia in primary lung cancer: observation of a possible precursor of the salivarytype isoamylase. Eur J Cancer Clin Oncol. 1982 Feb;18(2):123-8.

[7] Yoshida Y, Mori M, Sonoda T, Sakauchi F, Sugawara H, Suzuki A. Ultrastructural, immunohistochemical and biochemical studies on amylase and ACTH producing lung cancer. Virchows Arch A Pathol Anat Histopathol. 1985;408(2-3):163-72.

[8] Tomita N, Matsuura N, Horii A, Emi M, Nishide T, Ogawa M, et al. Expression of alpha-amylase in human lung cancers. Cancer Res. 1988 Jun 1;48(11):3292-6.

[9] Tsukawaki M, Izawa M, Yoshida M, Araki N, Hashiba Y, Nakagawa H, et al. A case of amylase-producing lung cancer. Intern Med. 1992 Jan;31(1):60-3.

[10] Grove A. Amylase in lung carcinomas. An ultrastructural and immunohistochemical study of two adenocarcinomas, and a review of the literature. APMIS. 1994 Feb; 102(2):135-44.

[11] Lenler-Petersen P, Grove A, Brock A, Jelnes R. alpha-Amylase in resectable lung cancer. Eur Respir J. 1994 May;7(5):941-5.

[12] Shimamura J, Fridhandler L, Berk JE. Nonpancreatic-type hyperamylasemia associated with pancreatic cancer. Am J Dig Dis. 1976 Apr;21(4):340-5.

[13] Nomura H, Tokumitsu SI, Takeuchi T. Ultrastructural, cytochemical, and biochemical characterization of alpha-amylase produced by human gastric cancer cells in vitro. J Natl Cancer Inst. 1980 May;64(5):1015-24.

[14] Ueda G, Yamasaki M, Inoue M, Tanaka Y, Inoue $Y$, Nishino T, et al. Immunohistochemical demonstration of amylase in endometrial carcinomas. Int J Gynecol Pathol. 1986;5(1):47-51.

[15] Corlette MB, Dratch M, Sorger K. Amylase elevation attributable to an ovarian neoplasm. Gastroenterology. 1978 May;74(5 Pt 1):907-9.

[16] Nakayama T HY, Kitamura M, editor. Onco-developemental gene expression. New York: Academic Press; 1976: 455-62.

[17] Masiar PJ. Serum amylase and isoamylases in malignant bone tumors. Neoplasma. 1984;31(3):351-9.

[18] Hata H, Matsuzaki H, Tanaka K, Nomura H, Kagimoto T, Takeya M, et al. Ectopic production of salivary-type amylase by a IgA-lambda-type multiple myeloma. Cancer. 1988 Oct 15;62(8):1511-5.

[19] Fujii H, Yashige H, Kanoh T, Urata Y. Amylase-producing multiple myeloma. Arch Pathol Lab Med. 1991 Sep;115(9):952-6.

[20] Delannoy A, Hamels J, Mecucci C, Fally P, Wallef G, de Fooz C, et al. Amylase-producing IgD-type multiple myeloma. J Intern Med. 1992 Nov;232(5):457-60. 
[21] Matsuyama M, Inoue T, Ariyoshi Y, Doi M, Suchi T, Sato T, et al. Argyrophil cell carcinoma of the uterine cervix with ectopic production of ACTH, beta-MSH, serotonin, histamine, and amylase. Cancer. 1979 Nov;44(5):1813-23.

[22] Weitzel JN, Pooler PA, Mohammed R, Levitt MD, Eckfeldt JH. A unique case of breast carcinoma producing pancreatic-type isoamylase. Gastroenterology. 1988 Feb; 94(2):519-20.

[23] Inaji H, Koyama H, Higashiyama $M$, Noguchi S, Yamamoto H, Ishikawa O, et al. Immunohistochemical, ultrastructural and biochemical studies of an amylase-producing breast carcinoma. Virchows Arch A Pathol Anat Histopathol. 1991;419(1):29-33.

[24] Sudo K, Kanno T. Sialic acid containing abnormal amylases in human sera. Clin Chim Acta. 1975 Nov 3;64(3):303-6.

[25] Moriyama T, Tozawa T, Yamashita H, Onodera S, Nobuoka M, Makino M. Separation and characterization of sialic acid-containing salivary-type amylase from patients' sera with immunoglobulin A-type myeloma. J Chromatogr. 1991 Nov 15;571(1-2):61-72.

[26] Moriyama T, Tozawa T, Nobuoka M, Ikeda H. Sialyl salivary-type amylasemia associated with immunoglobulin D-type multiple myeloma. Clin Chim Acta. 1995 Jan $16 ; 233(1-2): 127-34$.

[27] Shigemura M, Moriyama T, Endo T, Shibuya H, Suzuki H, Nishimura M, et al. Myeloma cells produce sialyl salivary-type amylase. Clin Chem Lab Med. 2004;42(6): 677-80.

[28] Yokouchi H, Yamazaki K, Asahina H, Shigemura M, Moriyama T, Takaoka K, et al. Establishment and characterization of amylase-producing lung adenocarcinoma cell line, IMEC-2. Anticancer Res. 2006 Jul-Aug;26(4B):2821-7.

[29] Moriyama T. Sialyl salivary-type amylase associated with ovarian cancer. Clin Chim Acta. 2008 May;391(1-2):106-11.

[30] Sandiford JA, Chiknas SG. Hyperamylasemia and ovarian carcinoma. Clin Chem. 1979 Jun;25(6):948-50.

[31] Cramer SF, Bruns DE. Amylase-producing ovarian neoplasm with pseudo-Meigs' syndrome and elevated pleural fluid amylase: case report and ultrastructure. Cancer. 1979 Nov;44(5):1715-21.

[32] Norwood SH, Torma MJ, Fontenelle LJ. Hyperamylasemia due to poorly differentiated adenosquamous carcinoma of the ovary. Arch Surg. 1981 Feb;116(2):225-6.

[33] Takeuchi T, Fujiki H, Kameya T. Characterization of amylases produced by tumors. Clin Chem. 1981 Apr;27(4):556-9. 
[34] Shapiro R, Dropkin R, Finkelstein J, Aledort D, Greenstein AJ. Ovarian carcinomatosis presenting with hyperamylasemia and pleural effusion. Am J Gastroenterol. 1981 Oct;76(4):365-8.

[35] Hodes ME, Sisk CJ, Karn RC, Ehrlich CE, Lehrner LM, Roth LM, et al. An amylaseproducing serous cystadenocarcinoma of the ovary. Oncology. 1985;42(4):242-7.

[36] Hayakawa T, Kameya A, Mizuno R, Noda A, Kondo T, Hirabayashi N. Hyperamylasemia with papillary serous cystadenocarcinoma of the ovary. Cancer. 1984 Oct 15;54(8):1662-5.

[37] Yagi C, Miyata J, Hanai J, Ogawa M, Ueda G. Hyperamylasemia associated with endometrioid carcinoma of the ovary: case report and immunohistochemical study. Gynecol Oncol. 1986 Oct;25(2):250-5.

[38] Teshima H, Kitamura H, Mizoguchi Y, Hino S, Mizutani K, Mori H, et al. Immunohistochemical and immunoelectron microscopic study of an amylase-producing, CA19-9 positive ovarian mucinous cystadenocarcinoma. Gynecol Oncol. 1988 Jul; 30(3):372-80.

[39] Schlikker I, Nakad A, Gerbaux A, Azzouzi K, Kadou J, Lezaire P, et al. Hyperamylasemia with papillary serous cystadenocarcinoma of the ovary. Acta Clin Belg. 1989;44(4):255-8.

[40] Brophy CM, Morris J, Sussman J, Modlin IM. "Pseudoascites" secondary to an amylase-producing serous ovarian cystadenoma. A case study. J Clin Gastroenterol. 1989 Dec;11(6):703-6.

[41] Tohya T, Shimajiri S, Onoda C, Yoshimura T. Complete remission of ovarian endometrioid adenocarcinoma associated with hyperamylasemia and liver metastasis treated by paclitaxel and carboplatin chemotherapy: a case report. Int J Gynecol Cancer. 2004 Mar-Apr;14(2):378-80.

[42] Srivastava R, Fraser C, Gentleman D, Jamieson LA, Murphy MJ. Hyperamylasaemia: not the usual suspects. BMJ. 2005 Oct 15;331(7521):890-1.

[43] Kavitha S, Balasubramanian R. Elderly lady with ascites. J Assoc Physicians India. 2006 Apr;54:325-6.

[44] Kosches DS, Sosnowik D, Lendvai S, Bank S. Unusual anodic migrating isoamylase differentiates selected malignant from nonmalignant ascites. J Clin Gastroenterol. 1989 Feb;11(1):43-6.

[45] Henriksen R, Brock A. Amylase activity and fast-migrating amylase isoenzymes in serum and cyst fluid from patients with ovarian neoplasms. Acta Obstet Gynecol Scand. 1988;67(1):65-70. 
[46] Bruns DE, Mills SE, Savory J. Amylase in fallopian tube and serous ovarian neoplasms: immunohistochemical localization. Arch Pathol Lab Med. 1982 Jan;106(1): 17-20.

[47] Kohn J. Separation of haemoglobins on cellulose acetate. J Clin Pathol. 1969 Jan;22(1): 109-11.

[48] Leclerc P, Forest JC. Electrophoretic determination of isoamylases in serum with commercially available reagents. Clin Chem. 1982 Jan;28(1):37-40.

[49] Gerber M, Naujoks K, Lenz H, Gerhardt W, Wulff K. Specific immunoassay of alphaamylase isoenzymes in human serum. Clin Chem. 1985 Aug;31(8):1331-4.

[50] Moriyama T YK, Takebe T, Makino I, Nobuoka M, Makino M. Purification of the pancreatic stone protein by high-performance liquid chromatography. J Chromatogr. 1989;493:164-9.

[51] Zakowski JJ, Bruns DE. Improved DEAE-Sephadex column chromatography in measuring amylase in serous ovarian neoplasms, and results for 13 cases. Clin Chem. 1982 Oct;28(10):2095-8.

[52] Zakowski JJ, Gregory MR, Bruns DE. Amylase from human serous ovarian tumors: purification and characterization. Clin Chem. 1984 Jan;30(1):62-8.

[53] Warshaw AL, Lee KH. Aging changes of pancreatic isoamylases and the appearance of "old amylase" in the serum of patients with pancreatic pseudocysts. Gastroenterology. 1980 Dec;79(6):1246-51.

[54] Weaver DW, Bouwman DL, Walt AJ, Clink D, Sessions S, Stephany J. Aged amylase: a valuable test for detecting and tracking pancreatic pseudocysts. Arch Surg. 1982 May;117(5):707-11.

[55] Shigemura M, Moriyama T, Shibuya H, Obara M, Endo T, Hashino S, et al. Multiple myeloma associated with sialyl salivary-type amylase. Clin Chim Acta. 2007 Feb; 376(1-2):121-5.

[56] Ward JC, Merritt AD, Bixler D. Human salivary amylase: genetics of electrophoretic variants. Am J Hum Genet. 1971 Jul;23(4):403-9.

[57] Moriyama T NM, Ikeda H. Properties of dominant amylase-2 found in routine electrophoreric analysis. Jpn J Electroph. 1995;39:195-200.

[58] Zakrzewska I, Pietrynczak M. [Changes in activity of alpha amylase and its salivary isoenzyme in serum and urine after surgical treatment of ovarian neoplasms]. Ginekol Pol. 1996 Oct;67(10):504-9.

[59] Zakrzewska I, Pietrynczak M. The alterations in the activity of amylase and its salivary isoenzyme in the serum of patients with ovarian carcinoma, submitted to radiotherapy. Rocz Akad Med Bialymst. 1997;42(1):229-35. 
[60] Seyama K, Nukiwa T, Takahashi K, Takahashi H, Kira S. Amylase mRNA transcripts in normal tissues and neoplasms: the implication of different expressions of amylase isogenes. J Cancer Res Clin Oncol. 1994;120(4):213-20.

[61] Bast RC, Jr., Xu FJ, Yu YH, Barnhill S, Zhang Z, Mills GB. CA 125: the past and the future. Int J Biol Markers. 1998 Oct-Dec;13(4):179-87.

[62] Bast RC, Jr., Badgwell D, Lu Z, Marquez R, Rosen D, Liu J, et al. New tumor markers: CA125 and beyond. Int J Gynecol Cancer. 2005 Nov-Dec;15 Suppl 3:274-81. 
